\title{
PREPAREDNESS, ACCEPTANCE, AND COMMITMENT AS PREDICTORS OF EFFICACY OF THE WELLNESS PROGRAM FOR DRUG SURRENDERERS
}

\author{
*Arjay Y. Alvarado
}

\begin{tabular}{l}
\hline Paper Received: 26.02.2020 / Paper Accepted: 30.05.2020 / Paper Published: 03.06.2020 \\
Corresponding Author: Arjay Y. Alvarado; Email: alvarado.arjay.y@ gmail.com; doi:10.46360/globus.xxxxxxxx
\end{tabular}

\begin{abstract}
This correlational study anchored on the Model of Community-based Treatment, and Seligman's Positive Psychology utilized Multiple Regression Analysis to investigate the levels of preparedness, acceptance, and commitment of illicit drug surrenderers who voluntarily surrendered, enrolled, and graduated from the wellness program in a selected local government unit in Negros Occidental, Philippines and to see if these three domains are related and predictors of the efficacy of the program. The wellness program for drug surrenderers is the first step of Community Based Rehabilitation Program of the national government - a jump start to the rehabilitation of the surrenderers. Results showed that the levels of preparedness and acceptance of the respondents are "High", whereas, their level of commitment is "Moderate". Taken collectively, the respondents' perceived efficacy of the wellness program is "Moderate". There were no significant differences in the level of efficacy of the wellness program as perceived by the respondents in all aspects of their demographic profile. Respondents' preparedness toward rehabilitation is significantly related to their perceived level of efficacy of the wellness program. Moreover, preparedness is the best predictor of efficacy. Acceptance and commitment domains are not related and predictors of efficacy of the wellness program.
\end{abstract}

Keywords: Wellness Program, Communitybased Rehabilitation Program, Multiple Regression, Drug Surrenderers.

\section{Introduction}

In the year 2016, Filipinos catapulted President Rodrigo Roa Duterte to presidency. Prior to his election, he underscored in many of his speeches that if he will be elected he will wage war on drugs. True to his words, on July 2016 he declared war on illicit drugs - the flagship of his administration. This effort to eradicate the illicit drugs was dubbed as 'Operation Double Barrel' or Oplan Tokhang. Tokhang came from two contracted Visayan word, toktok-hangyo, or to knock and plead. The campaign involved efforts to reduce the supply and demand of illicit drugs all over the country spearheaded by the Philippine National Police together with local officials they visit homes of known users and asked them to voluntarily surrender and receive treatment.

As of March 2017, 1.18 million illicit drug users have surrendered (Raymundo, 2017). However, beyond these voluntary surrenderers an additional 44,070 arrests and 2,206 fatalities (Palatino, 2017) were recorded (as cited in Hechanova, et. al., 2018). In addition, there are cases of extra-judicial killings as noted by the Human Rights Watch (2017). In their report, the Philippine National Police and unidentified vigilantes have killed about 7,000 suspected drug users and pushers. The selected local government unit in this study has actively answered on this call and has its share of voluntary surrenderers.

The overwhelming number of surrenderers accentuated the urgent need to develop and implement drug treatment programs. Comparatively, Health Secretary, Dr. Paulyn Ubial, highlighted that the increasing number of drug surrenderers in the country demonstrates that it is a public health emergency (Rappler, 2016). However, because drug treatments are costly and generally inaccessible to the poor, the UNODC (2014) suggested the necessary provision of community-based drug recovery support. This involves providing holistic care in the form of preventive education, health promotion, screening, treatment and rehabilitation services, primary health services, basic support, education, skills training, and livelihood opportunities in communities (UNODC, 2014). The framework for the community-based drug recovery support was advanced by the Department of Health and the first 
step of this program is a wellness camp for drug surrenderers.

The wellness program as the first step served as a jumpstart to the rehabilitation of the surrenderers, to equip them with necessary skills to help them cope with the transition brought about by rehabilitation. It was designed to be five days livedin where surrenderers are secured and free from drugs, cigarettes, and alcohol. This five day program includes activities such as learning sessions, lectures, and workshops conducted by experts in the field of addiction works and rehabilitation, counseling, spiritual growth, and industry among others. The learning sessions, lectures, and workshops include topics on SelfCare, Healthy Lifestyles, Problem Solving Skills, Effect of Drugs and its Legal Consequences, Anger Management, Facing My Traumatic Past, Values Reformation, Enriching Spiritual Life, Facing Social Stigma, and Trust Building. Moreover, each night surrenderers submit themselves to an AccuDetoxification before going to bed. A one-onone processing conducted by counselors and social workers every night further strengthen the learning sessions by helping them contextualize and apply what they have learned. Also, the counselors and social workers provide them with guidance by coaching them on their personal recovery plan that they will carry out after finishing the wellness camp. The last day of the wellness camp is dedicated for the surrenderers together with their family members, this session focuses on Family Healing and Reconciliation and Facing and Encounter with Family Members. Each cycle of wellness camp culminates with a graduation rites usually in the afternoon of the last day, the surrenderer-graduates are enjoined by their family and local officials.

The researcher, a volunteer counseler/therapist and at times resource speaker of the wellness camp deemed it necessary to determine the efficacy of the program as anchored on its objectives because he had noticed that the only mean that takes into account the perception of the participants towards the program is through a widely used feedback evaluation form that they rate in terms of the content and coverage, facilitators/staff, venue, sleeping quarter/accommodation, and food. He deemed necessary to developed an instrument that captures the experience of the participants whether the program is effective or not based on its given objectives since the feedback evaluation form does not capture its essence.

It is noteworthy however, that the researcher had observed and confirmed by other counselors in the one-on-one sessions some areas of concerns put forth by some surrenderers. Firstly, they are not prepared to join the wellness camp (e.g. financial, emotional); second, they are ambivalent of their status with regard to drug use (e.g. they believed that they are not an addict rather they are merely users); and, lastly, they lack commitment towards recovery, some believed that the problem of drugs is deeply rooted and they are unsure once they finish the wellness camp if they can manage saying "no" to drugs. It is essential then that the surrenderers' preparedness, acceptance, and commitment towards rehabilitation be taken into account to see its influence on the efficacy of the program.

This research may be the pioneering research conducted on the first step of the Community-based Rehabilitation Program in the selected local government unit if not the forerunner research in the whole province of Negros Occidental, Philippines. This research will also become the springboard for future researches, the results and recommendations of this study may add to the very limited and novel literature of the topic being discussed.

Generally, this study aims to determine the efficacy of the Wellness Camp - $1^{\text {st }}$ Step Road to Recovery Program for drug surrenderers in a local government unit in the province of Negros Occidental, Philippines and to identify the variables that best predict such efficacy. Specifically, this study purports to answer the following questions:

1. What is the profile of the respondents in the wellness program for drug surrenderers in terms of their:
a. Civil Status; b. Age;
b. Educational Attainment; and
c. Preferred substance used?

2. What is the level of preparedness, acceptance, and commitment of the respondents toward drug use when taken as a whole and when grouped according to the abovementioned profile variables?

3. What is the efficacy of the wellness program as perceived by the respondents when taken as a whole and when grouped according to the abovementioned profile variables?

4. Is there a significant difference in the efficacy of the wellness program as perceived by the respondents when grouped according to the abovementioned profile variables?

5. Is there a significant relationship between the level of preparedness, acceptance, and commitment of the respondents toward drug use and their perceived efficacy of the wellness program?

6. Does the level of preparedness, acceptance, and commitment of the respondents toward drug use predict their perceived efficacy of the wellness program? 
Based on this research's inferential objectives, the following null hypotheses were formulated:

1. There is no significant difference in the efficacy of the wellness program as perceived by the respondents when grouped according to the abovementioned profile variables.

2. There is no significant relationship between the level of preparedness, acceptance, and commitment of the respondents toward drug use and their perceived efficacy of the wellness program.

3. The level of preparedness, acceptance, and commitment of the respondents toward drug use do not predict their perceived efficacy of the wellness program.

This study was anchored on three models/framework that will be presented in topdown fashion for better understanding. Broadly starting from the World Health Organization Pyramid of Mental Health Services, followed by the Model of Community-based Treatment, and Seligman's Positive Psychology.

The first framework shows that the core goal of the community-based treatment model is to ensure a holistic approach to treatment and care of drug users with the intensity of essential care varied according to the nature and complexity of the problems experienced by the individual. As such the approach is broadly based on the World Health Organization Pyramid of Mental Health Services (UNODC, 2008).

Key principles of community-based treatment are: Continuum of care from outreach, basic support and harm reduction to social reintegration, with no "wrong door" for entry into the system; Delivery of services in the community - as close as possible to where drug users live; Minimal disruption of social links and employment; Integrated into existing health and social services; Involve and build on community resources, including families; Participation of people who are affected by drug use and dependence, families and the communityat-large in service planning and delivery; Comprehensive approach, taking into account different needs (health, family, education, employment, housing); Close collaboration between civil society, law enforcement and the health sector; Provision of evidence-based interventions; Informed and voluntary participation in treatment; Respect for human rights and dignity, including confidentiality; Acceptance that relapse is part of the treatment process and will not stop an individual from re-accessing treatment services.

The second model reflects the complexity of identification, diagnosis and treatment interventions for people who affected by drug use and dependence in the community. It is clear that there is no one identifiable single entry point into the treatment and intervention system. Drug users may, if they so wish, go directly to the health centre or hospital or specialised clinic, or request assistance from government agencies or NGOs. Consequently, the model may be best described in a circular form around the individual client/patient rather than linearly.

The combination of services provides a continuum of care from informal community care and community outreach services, to drug withdrawal, counselling, aftercare, rehabilitation and reintegration.

The model provides the basis for close collaboration between NGOs, health and social support services at the village or community level, and provides a focal point for regular liaison between local law enforcement agencies and the community. Such a mechanism includes the raising of awareness among law enforcement officials of their role in facilitating access to health and social services for people with drug-related problems as an alternative to punitive sanctions.

The third model is the Positive Psychology Model by Martin Seligman. Positive psychology is the scientific study of the strengths and virtues that enable individuals and communities to thrive. The field is founded on the belief that people want to lead meaningful and fulfilling lives, to cultivate what is best within them, and to enhance their experiences of love, work, and play some goals of Positive Psychology are to build a science that supports families and schools that allow children to flourish, workplaces that foster satisfaction and high productivity, communities that encourage civic engagement and therapists who identify and nurture their patients' strengths. Positive Psychology Center (PSC) (2007).

It is worth noting that Seligman recognize that a complete science and a complete practice of psychology should include an understanding of suffering and happiness, as well as their interaction" but they consider relief in suffering and enhancement of happiness as "two separate endeavours. Positive Psychology, are inherently interdependent endeavours. The focus on what is good about people in times of peace and prosperity is only half of the story. The whole story of Positive Psychology is about how to bring out the best in people in good and bad times in spite of their internal and external limitations (Wong, 2011).

One of the models developed from Positive Psychology are the wellness models. These models 
focused on positive psychology and attempted to determine and correlates between health, quality of life, and longevity (Myers \& Sweeney, 2005). These early models have given way to more evidence-based models intended to inform clinical practice. A new paradigm in medicine emerged in which body, mind, and spirit are seen as integral to understanding both health and wellness (Larson, 1999; Myers\& Sweeney, 2008). Many early models of wellness came from the perspective of the medical field (Myers \& Sweeney, 2005). These models focused on establishing a differentiation between being ill and being well. The area of wellness was then addressed in the mental health professions, specifically counseling, beginning in the early 1990s.

The aforementioned model is the framework of the wellness program for drug surrenderers in the selected local government unit in the province of Negros Occidental, Philippines, hence, the learning sessions in the program are anchored on the body, mind, and spirit.

Wellness dates back to many years ago. Many different models have been developed to provide a framework for understanding wellness. Body, mind, and spirit are the most commonly recognized areas of wellness. The roots of wellness go back almost 2,000 years. The Greek Philosopher Aristotle, writing in the $5^{\text {th }}$ century B.C. was perhaps the first person to write about wellness. His goal in doing so was to offer a scientific explanation for health and illness and to define a model of good health in which one seeks for "nothing in excess".

Myers, Sweeney, and Witmer (2000) to propose a comprehensive definition of wellness as: "a way of life oriented toward optimal health and well-being, in which body, mind and spirit are integrated by the individual to live life more fully within the human and natural community. Ideally, it is the optimum state of health and well-being that each individual is capable of achieving.

On the other hand, Travis \& Ryan (2004) stated that high-level wellness involves giving good care to yourself, using your mind constructively, expressing your emotions effectively, being creatively involved with those around you, and being concerned about your physical, psychological, and spiritual environments.

\section{Methodology}

This study utilized relational design; relational studies' distinguishing characteristic according to Fox (1969, as cited in Ardales, 2008) is its system, which allows estimation of relationship between study variables. In the explanation purpose of correlation, the researcher was able to find out whether the relationship between variables is positive or negative or significant or not, in this study, the level of preparedness, acceptance, and commitment of the respondents and their perceived efficacy of the wellness program were tested. Furthermore, in the prediction purpose of correlation allows a researcher to estimate the linear or straight line, relationship that relates two or more variables. This linear relationship summarizes the amount of change in one variable that is associated with change in another variable or variables. The model can also be tested for statistical significance, to test whether the observed linear relationship (variables mentioned above) could have emerged by chance or not, hence, the predicting power.

The respondents of this study were the drug surrenderers who voluntarily surrendered in the selected local government unit in the province of Negros Occidental, Philippines who were screened, enrolled, successfully finished and graduated in the wellness program. The list of graduated participants was obtained by the researcher from the gatekeeper of the said local government unit.

Out of 296 surrenderers the sample size was 170 . Samples were drawn using simple random sampling design to ensure the random selection of the respondents.

The researcher made use of a self-made instrument that measures the perceptions of the respondents regarding their Preparedness, Acceptance, and Commitment toward drug use and the Efficacy of wellness program.

Part I is the Respondents' Profile Questionnaire, it is made up of questions pertaining to the participants' personal circumstances including name (optional), age, marital status, educational attainment, and preferred substance used.

Part II is the Preparedness Questionnaire, it is made up of questions pertaining to the preparedness of the respondents toward rehabilitation, and recovery and joining the wellness camp.

Part III is the Acceptance Questionnaire, it is made up of questions pertaining to the acceptance of the respondents toward rehabilitation and recovery, and joining the wellness camp.

Part IV is the Commitment Questionnaire, it is made up of questions pertaining to the commitment of the respondents toward rehabilitation and recovery, and joining the wellness camp. 
Part V is the Efficacy Questionnaire, it is made up of questions pertaining to the perceived impact of the wellness camp to the respondents.

All items are provided with Hiligaynon translation. For Preparedness Questionnaire, initially, there were ten items. After the panelist peruse all the items, two items yield a CVR of .6, these item were then dropped and not included in the questionnaire. For Acceptance Questionnaire, all ten items produce a CVR of 1.0, all items then are included in the questionnaire. The same case for Commitment Questionnaire, all ten items holds a CVR of 1.0, therefore, included in the questionnaire.

For Efficacy Questionnaire, out of 24 items only one item holds a CVR of .6 and therefore dropped. All the rest has a CVR of 1.0 .

The final instrument that were tested for reliability has eight items on Preparedness, 10 items on Acceptance, 10 items on Commitment, and 23 items on Efficacy.

The reliability coefficient of the instrument in terms of its internal consistency was solved with the use of Cronbach's Alpha. The reliability coefficients of the four scales were obtained from the results of twenty-eight respondents who graduated from the wellness program of Talisay City, Negros Occidental who shared and followed the same wellness model with Cadiz City. The following are the reliability coefficient for each scale: for Preparedness .835 (Good); for Acceptance .918 (Excellent); for Commitment .844 (Good); for Efficacy 845 (Good).

This research undertaking followed the subsequent procedures:

Firstly, the researcher wrote a letter address to the city mayor asking permission to conduct his research to his constituents underlining the rationale and benefits of the study. Once approved, the researcher then coordinated with the program consultant and the different offices in-charge to obtain the list of surrenderers who graduated from the program. Next, sampling was drawn from the list and the list of identified respondents was brought to the program consultant for confirmation of their availability. Subsequently, the next step was administration of the instrument to the selected respondents in a given venue. After the administration of the instrument, data collected were collated in Microsoft Excel, and then the researcher with the help of a statistician processed the data using the Statistical Package for Social Sciences.

\section{Results, Discussion and Implications}

As part of the first objective of this study, four (4) variables were used by the researcher in order to determine the profile of 170 respondents, these were civil status, age, educational attainment, and substance used.

In terms of civil status, almost half $(47.1 \%)$ of the respondents are single, which, among the respondents, was the most common civil status. Only a handful is divorced $(4.1 \%)$ or widowed (7.6\%). The rest are married.

With regard to age, the responses of the participants yielded a mean of 33.03 years and a median of 32 years. Using these data, the participants were then classified into two age groups - those who are Younger (respondents who are 32 years or younger) and those who are Older (respondents who are 33 years or older). More than half of the respondents $(51.8 \%)$ are categorized under the Younger group.

The largest group of participants is High School Graduates $(55.7 \%)$ in terms of Educational Attainment. This is followed by those who finished Elementary $(22.4 \%)$ and College (15.3\%). The remaining others have Graduate $(2.4 \%)$ or PostGraduate degrees (4.1\%).

In terms of the substance used, most of the participants $(76.5 \%)$ have identified that they used shabu. Less than a quarter of the total number of respondents $(23.5 \%)$ responded that they used marijuana.

When grouped according to their civil statuses, all groups of the respondents have High level of preparedness, with those who are Widowed yielding the highest mean level of preparedness (3.23). On the other hand, those who are Divorced scored the lowest (2.95).

All groups of the respondents have High level of acceptance, with those who are Married yielding the highest mean level of acceptance (2.89). On the other hand, those who are Single scored the lowest (2.81).

All groups of the respondents have Moderate level of commitment, with those who are Divorced yielding the highest mean level of commitment (2.77). On the other hand, those who are Married scored the lowest (2.74).

When the respondents are grouped according to age, both groups - Younger and Older - of the respondents have High level of preparedness, with those who are Older yielding the higher mean level 
of preparedness (3.16), while those who are Younger scored 3.09.

Both groups of the respondents have High level of acceptance, with those who are Older yielding the higher mean level of acceptance (2.89). On the other hand, those who are Younger scored 2.81.

Both groups of the respondents have Moderate level of commitment, with those who are Younger yielding the higher mean level of commitment (2.76). On the other hand, those who are Older scored the 2.71 .

When the respondents are grouped according to age, four groups - those who finished Elementary, High School, College, and Post Graduate - of the respondents have High level of preparedness. Those with Graduate yielded the highest mean level of preparedness at 3.41 which is interpreted as Very High, while those who have Post Graduate degrees scored the lowest with 2.82 .

All groups of the respondents have High level of acceptance, with those who have Graduate degrees yielding the highest mean level of acceptance (3.23). On the other hand, those who are Post Graduate degrees scored the lowest (2.81).

Four out of five groups of the respondents have Moderate level of commitment - namely Elementary, High School, Graduate, and Post Graduate degree holders. Those who have College degrees scored the highest mean level of commitment at 2.81, which is interpreted as High. Those who have Post Graduate degrees scored the lowest with a mean of 2.64.

When the respondents are grouped according to the kind of substance that they use, both groups Marijuana and Shabu users - of the respondents have High level of preparedness, with Marijuana users yielding the higher mean level of preparedness (3.15), while those who use Shabu scored 3.12 .

Both groups of the respondents have High level of acceptance, with those who using Marijuana yielding the higher mean level of acceptance (2.87). On the other hand, those who are using Shabu scored 2.84. As a whole, the respondents rated their levels of acceptance as High with a mean rating of 2.85 .

Both groups of the respondents have Moderate level of commitment, with those who are Shabu users yielding the higher mean level of commitment (2.76). On the other hand, those who are using Marijuana scored 2.68. As a whole, the respondents rated their levels of commitment as Moderate with a mean rating of 2.74 .

When grouped according to their civil statuses, all groups of the respondents have perceived the wellness program with High level of efficacy, except for grouped of the Divorced respondents who scored 2.60. Those who are Widowed yielding the highest mean level of perceived efficacy (2.83).

When grouped according to their age, the Older group of the respondents have perceived the wellness program with High level of efficacy (2.81). On the contrary, those who are Younger yielded a lower mean level of perceived efficacy at 2.80, which is interpreted as Moderate.

When grouped according to their educational attainment, the Graduate degree holder respondents have perceived the wellness program with High level of efficacy (3.07), this group gave the highest mean ratings among all groups. On the contrary, those who have Post Graduate degrees yielded the lowest mean level of perceived efficacy at 2.61, which is interpreted as Moderate.

Taken collectively, the efficacy of the wellness program as perceived by the respondents obtained a mean score of 2.80 which is interpreted as Moderate.

The Age group showed that there was no significant difference in the efficacy of the wellness program as perceived among respondent for Younger $(\mathrm{M}=2.8, \mathrm{SD}=0.29)$ and Older $(\mathrm{M}=2.81$, $\mathrm{SD}=0.3) ; \mathrm{t}(168)=-0.38, \mathrm{p}=0.706$.

Moreover, the Substance Used group also showed that there was no significant difference in the efficacy of the wellness program as perceived among respondent for Marijuana $(\mathrm{M}=2.9$, $\mathrm{SD}=0.41)$ and Shabu $(\mathrm{M}=2.78, \quad \mathrm{SD}=0.23)$; $\mathrm{t}(46.93)=1.77, \mathrm{p}=0.083$. Therefore, the results failed to reject the null hypotheses for both age and substance.

A one way ANOVA showed the differences in the efficacy between Single ( $\mathrm{n}=80, \mathrm{M}=2.79, \mathrm{SD}=$ $0.31)$, Married $(\mathrm{n}=70, \mathrm{M}=2.81, \mathrm{SD}=0.25)$, Divorced $(\mathrm{n}=7, \mathrm{M}=2.82, \mathrm{SD}=0.43)$ and Widowed $(\mathrm{n}=13, \mathrm{M}=2.77, \mathrm{SD}=0.31)$ were statistically not significant, $\mathrm{F}(3,166)=0.12, \mathrm{p}=$ 0.95 .

Also, a one way ANOVA showed the differences in the efficacy between Elementary ( $\mathrm{n}=38, \mathrm{M}$ $=2.82, \mathrm{SD}=0.33)$, High School $(\mathrm{n}=95, \mathrm{M}=2.83$, $\mathrm{SD}=0.29)$, College $(\mathrm{n}=26, \mathrm{M}=2.77, \mathrm{SD}=$ $0.24)$, Graduate $(n=4, M=2.46, S D=0.3)$ and Post Graduate $(\mathrm{n}=7, \mathrm{M}=2.7, \mathrm{SD}=0.17)$ were 
statistically not significant, $\mathrm{F}(4,165)=2.03, \mathrm{p}=$ 0.09 . The results failed to reject the null hypotheses for both groups.

It can be seen that the level of preparedness of the respondents and their perceived efficacy of the wellness program were strongly and significantly correlated, $\mathrm{r}(170)=.244^{* *}, \mathrm{p}=0.001$. Null hypothesis is therefore rejected.

Whereas, the level of acceptance of the respondents and their perceived efficacy of the wellness program were not significantly correlated, $\mathrm{r}(170)=$ $0.088, \mathrm{p}=0.252$. The result failed to reject the null hypothesis.

Moreover, the level of commitment of the respondents and their perceived efficacy of the wellness program were also not significantly correlated, $r(170)=0.139, p=0.071$. In this particular are the result failed to reject the null hypothesis.

Between efficacy and preparedness, a calculated tvalue of 3.26 with a p-value of .001 revealed that preparedness significantly predicted the efficacy of the wellness program. Null hypothesis is therefore rejected.

Between efficacy and acceptance, a calculated tvalue of 0.11 with a p-value of .909 revealed that acceptance do not significantly predicted the efficacy of the wellness program. The result failed to reject the null hypothesis.

Between efficacy and commitment, a calculated tvalue of 1.89 with a p-value of .061 revealed that commitment do not significantly predicted the efficacy of the wellness program. The result failed to reject the null hypothesis.

\section{Conclusion and Recommendations}

Based on the findings of this research, the following conclusions are drawn.

The drug surrenderers who finished the wellness program in a selected local government unit in Negros Occidental, Philippines are highly prepared for their rehabilitation highly accepted their status as illicit drug users and are moderately committed to the rehabilitation. The wellness program is perceived by the surrenderers with moderate efficacy or effectiveness. Also, the efficacy of the program does not vary with regard to the profile of the surrenders. Furthermore, surrenderers who are more prepared to get rehabilitated are most likely to benefit from the wellness program.

Based on the results, the following recommendations are advanced:
That surrenders prepare themselves (physically, mentally, emotionally, spiritually) prior to the wellness program to maximize the benefits they can get, since preparedness is an essential predictor of success of the program.

That people of the said local government unit provide an ample support to the surrenderers by accepting them without prejudices and stigma. Social support plays a vital role on recovery.

That City officials provide a preparedness program for the surrenderers prior to the wellness program. Assess the level of their preparedness and make it an inclusion criterion of enrollment in the program.

That mental health professional develop a program that takes into consideration of the surrenders preparedness, acceptance, and commitment towards recovery.

That future researchers make use of focus group discussion in conducting the same research to reveal a more personal aspect in the flavor of this topic. Also, to make use of more profile variables such as length of drug use and income to gain a clearer picture of the surrenderers.

\section{Conflict of Interest}

There is no Conflict of Interest in this work.

\section{References}

1. American Psychiatric Association, (2013). Diagnostic and statistical manual of mental disorders (5th ed.). Washington, D.C.: Author.

2. Ardales, V., (2008). Basic concepts and methods in research, $3^{\text {rd }}$ Edition. Manila: Educational Publishing House.

3. Agarwal, Nidhi and Jaiswal, Sushma, (2019). "A Study at Organizational Commitment of Educator in School". International Journal of Multidisciplinary Education and Research, 4(1), 39-41; doi: 10.5281/zenodo.3806468.

4. Agarwal, Nidhi (2018). "A study of innovations in instructional strategies and designs for quality enrichment in Higher Education". Cosmos: An International Journal of Art \& Higher Education, 7(2), ISSN: 23198966.

5. Arria, A.M., Garnier-Dykstra, L.M., Cook, E.T., Caldeira, K.M., Vincent, K.B., Baron, R.A., \& O'Grady, K.E., (2013). Drug use patterns in young adulthood and post-college employment. Drug and Alcohol Dependence, 127(1-3), 23-30. doi: http://dx.doi.org/ 10.1016 /j.drugalcdep.2012.06.001.

6. Ballentine, H.M., (2010). The Relationship Between Wellness and Academic Success in First-Year College Students. www.Proquest. com/socialsciences/docview 
7. Barlow, D. H. and Mark Durand, V., (2015). Abnormal psychology: An integrative approach, Seventh Edition. Connecticut: Cengage Learning.

8. Barwais, F., (2012). Definition of Wellbeing, Quality of Life and Wellness. http://nwia.idwellness.org/2011/02/28/definitio ns-of-wellbeing-quality-of-life-and-welllness.

9. Bautista, V.A., (2000). Research and public management. Quezon City: UP Open University Press.

10. Bhatti, M.I., (2011). Relationship Between Spiritual Wellness and Quality of Life among University Students. Pakistan Journal of Psychology, 42(2); 57-65.

11. Bigbee, A., (2008). The Relationship between Religion, Social Interest, and Wellness in Adults.search.proquest.com/socialsciences/doc view/759606027/140D84A30E64115A38E/17/ accountid=34542.

12. Cepeda, M., (2016). DDB wants law institutionalizing community-based drug treatment. Rappler. Retrieved from http://www.rappler.com/nation/147020ddblaw-institutionalize-community-baseddrug-rehabilitation

13. Corbin, C., (2004). Health, Wellness, Fitness and Healthy Lifestyles. Retrieved from:https://ph.search.yahoo.com/search;_ylt= ArJNV.cX5rfiBlG3rqIM0dMu4405? $\mathrm{p}=$ health+ and+Fitness+by+Corbin+et.+al\&toggle $=1 \&$ co $\mathrm{p}=\mathrm{mss} \& \mathrm{ei}=\mathrm{UTF}-8 \& \mathrm{fr}=\mathrm{yfp}-\mathrm{t}-711$

14. Dangerous Drug Board, (2016). Community based treatment and rehabilitation resources. Retrieved from http://www.ddb.gov.ph/sidebar/301community-basedtreatment-and-rehabilitationresources.

15. Dawson, D. A., Goldstein, R. B., \& Grant, B. F., (2012). Differences in the profiles of DSMIV and DSM-5 alcohol use disorders: Implications for clinicians. Alcoholism: Clinical and Experimental Research, 37(S1); E305-E313 doi: 10.1111/j.15300277.2012.01930.x.

16. DOH, (2016). Guide for community-based assessment, treatment and care services for drug. Retrieved from http://www.unodc.org/Publications/CBT_Guid ance_Doc_Philippines_Finals.pdf.

17. Dufour, C., (2010). Check Your Emotional and Mental Health for Total WellBeinghttp;//www.buzzle.com/articles/checkyour-emotional-and-mental-health-for-totalwell-being.html.

18. Edwards, G., (2012). "The Evil Genius of the Habit": DSM-5 seen in historical context. Journal of Studies on Alcohol and Drugs, 73(4); 699.
19. Ehlers, C., Gizer, I., Vieten, C., Gilder, D., Stouffer, G., Lau, P., \& Wilhemsen, K.C., (2010). Cannabis dependence in the San Francisco Family Study: Age of onset of use, DSM-IV symptoms, withdrawal, and heritability. Addictive Behaviors, 35(2); 102110.

20. Egeberg, J.W., (2008). Wellness Promotion on the Campus of Two-Year and Four Year Colleges and Universities. Retrieved from: Proquest LLC, 2013.

21. Everhart, K., (2013). The Impact of Course Delivery Format on Wellness Patterns of University Students.search.proquest.com/ socialsciences/docview/759606027/140D84A3 0E64115A38E/17/accountid=34542.

22. Filkowski, M.B., (2008). Leadership for campus Mental Wellness. Retrieved from: Proquest LLC (2013).

23. Gavilan, J., (2015). DDB: Philippines has 1.8 Million Current Drug Users, (Updated on October 11, 2016). Retrieved from http://www.rappler.com/nation/146654-druguse-survey-results-dangerous-drugs-boardphilippines-2015.

24. Gibson, M., (2006). Perceived Stress, Wellness, and Mattering: A Profile of First Year Citadel Cadets. Retrieved from PROQUEST, 2013.

25. Golan, M., (2014). Gender Related Differences in Response to "In favour of Myself" Wellness Program to enhance Positive Self \& Body Image among Adolescemnts:e91778.

26. Gonzales, R., (2013). Body and Health, Mind and Wellness II: The Mechanisms Behind the Effects of a Psycho-Educative Intervention. Research in Psychology and Behavioral Sciences, 1(5); 67-76.

27. Hechanova, M.R.M., Alianan, A.S., Calleja, M.T., Melgar, I.E., Acosta, A., Villasanta, A., Bunagan, K., Yusay, C., Ang, A., Flores, J., Canoy, N., Espina, E., Gomez, G.A., Hinckley, E. S., Tuliao, A.P. and Cue, M.P., (2018). The development of a community-based drug intervention for Filipino drug users. Journal of Pacific Rim Psychology, 12 (12).

28. Higgins, S.T., Sigmon, S.C., \& Heil, S.H. (in press). Drug use disorders. In D.

29. H. Barlow, (Ed.), Clinical handbook of psychological disorders: A step-by-step treatment manual. New York, NY: Guilford.

30. Higgins, J.W., (2010). Wellness 101: health education for the university student. Health Education, 110.4 (2010): 309-327. http://serachproquest.com/docview/578109680 /C5C0905706EE4CD4

31. Higgins, W., (2009). University Students' Wellness - What difference can a course make? College Student Journal 43.3 (Sep 2009): 766-777. Search.proquest.com/docview 
/236482414/140D898553FA959CE/7?accounti $\mathrm{d}=34542$.

32. Hilton, C., (2011). Healthy Habit Changes in Pre-Professional College Students: Adherence, Supports, and Barriers. search.proquest.com/ socialsciences/docview/861402182/140E18DF A1F53495271/5? accountid=34542.

33. Innstrand, S.T., (2011). Exploring within- and between-gender differences in burnout: 8 different occupational groups.Int Arch Occup Environ Health, 84:813-824.

34. Johnston, L. D., O’Malley, P. M., Bachman, J. G., \& Schulenberg, J. E. (2011). Monitoring the Future national results on adolescent drug use: Overview of key findings, 2010. Ann Arbor, MI: Institute for Social Research.

35. Kelly, T.M., (2004). Positive Psychology and Adolescent Mental Health: False Promise or True Breakthrough? Retrieved from : PROQUEST LLC, 2014)

36. Leamon, M.H., Wright, T.M. and Myrick, H., (2008). Substance-related disorders. In R. E. Hales, S. C. Yudofsky, \& G. O. Gabbard (Eds.), The American Psychiatric Publishing textbook of psychiatry (5th ed., pp. 365-406). Arlington, VA: American Psychiatric Publishing. Marital Status. Retrieved from http://nap.psa.gov.ph/glossary/terms/indicator Details.asp?strIndi=66.

37. Maajeeny, Hassan, (2019). Children With Emotional and Behavioral Disorders in Saudi Arabia: A Teacher Preliminary Screening. Globus Journal of Progressive Education, 9(2); 4-10, doi: 10.46360/globus.9.2.2020.4-10.

38. National Anti-Drug Plan of Action 2015-2020, p1. NSDUH. (2010). Results from the 2009 National Survey on Drug Use and Health: Volume 1. Summary of national findings. (Office of Applied Studies, NSDUH Series H38a.) Rockville, MD: Substance Abuse and Mental Health Services Administration.

39. O'Brien, C., (2011). Addiction and dependence in DSM-V. Addiction, 106(5), 866-867.

40. Palatino, M., (2017). Duterte's 'War on illicit drugs' in the Philippines: By the numbers. The Diplomat. Retrieved from http://thediplomat.com/2017/ 01/dutertes-war- on-illicitdrugs-in-the-philippines-by-

thenumbers/

41. Philippine Drug Enforcement Agency (PDEA), (2015). PDEA Annual Report. Retrieved from http://pdea.gov.ph/our-

accomplishments/annual-reports.Preferred.

Retrieved from cambridge.org.

42. Raymundo, P.T., (2017). PNP resumes tokhang to look into $1.18 \mathrm{M}$ drug surrenderees. Retrieved from http://www.canadianinquirer.net/2017/03/11/p np-resumestokhang-to-look-into-1-18-m-drugsurrenderees/

43. Sharma, Juhi, (2018). The Impatience in Apprehending Education within Social Digitalized Media. Globus An International Journal of Management \& IT, 10(1); 20-22, ISSN: 0975-721X.

44. Students from University of the Philippines, EXPLAINER: How Serious is the PH Drug Problem? Here's the Data, August 27, 2016 (updated on September 19, 2016). Retrieved from

http://www.rappler.com/newsbreak/iq/144331data-drug-problem-philippines

45. Thorley, A., (1980), "Medical responses to problem drinking". Medicine, $3^{\text {rd }}$ Series, 35:1816-1833.

46. UNODC, (2014). Guidance for communitybased treatment and care services for people affected by drug use and dependence in Southeast Asia. Retrieved from http://www/unodc.org/cbtx_EN

47. UNODC, (2008). TREATNET - Drug dependence treatment: Sustained recovery management. Good practice document. Retrieved from http://www.unodc.org/docs/ treatment/111SUSTAINED_RECOVERY_M ANAGEMENT.pdf.

48. Villar, M., (2015). The Drug Problem and the Economy, June 15, 2015. Retrieved from http://www.businessmirror.com.ph/the drugproblem-and-the-economy/

49. WHO Lexicon of alcohol and drug terms. Retrieved from http://www.who.int/substance _abuse/terminology/who_lexicon/en/ http://www.who.int/substance_abuse/terminolo gy/who_lexicon/en/

How to cite this article:

Alvarado, Arjay Y., (2020). Preparedness, Acceptance, and Commitment as Predictors of Efficacy of The Wellness Program for Drug Surrenderers. Globus Journal of Progressive Education, 10(1): 111-119. 